\title{
How Much has COVID-19 Pandemic Affected Indian Orthopaedic Practice? Results of an Online Survey
}

\author{
Kumar Keshav ${ }^{1} \cdot$ Amit Kumar $^{1} \cdot$ Pulak Sharma $^{1} \cdot$ Anurag Baghel $^{1} \cdot$ Prabhaker Mishra $^{2} \cdot$ Najmul Huda $^{3}$
}

Received: 3 June 2020 / Accepted: 28 July 2020 / Published online: 4 August 2020

(c) Indian Orthopaedics Association 2020

\section{Abstract}

Backgroud Coronavirus Disease 2019 (COVID-19) has spread globally affecting all strata of people including the orthopaedic surgeons of India. We have witnessed a drastic fall in the number of patients. The aim of study was to assess the extent to which the Indian orthopaedic practice has been affected by the pandemic.

Methods We conducted an online survey amongst currently practicing Indian orthopaedic surgeons. Those currently not in practice or under training or having left clinical practice before the onset of pandemic were excluded. A total of 533 orthopaedic surgeons took part in the study amongst which, complete responses were obtained from 407 individuals. Statistical analysis was done to see the association between demographic profile of study participants and various variables of orthopaedic practice.

Results There was drastic fall in all the parameters of orthopaedic practice. Over half of the practicing surgeons witnessed fall in out-patients over 90\%. Most had stopped elective surgeries (64\%) and even emergency ones (21\%) altogether. More than $50 \%$ of doctors had their earnings reduced by $>75 \%$. We found a statistically highly significant association of reduction in earnings with the sector, type of set-up and duration of practice. ( $p$-value $<0.001$ ).

Conclusion This study suggests that orthopaedic surgeons across all sectors in different kinds of set-ups have been affected in their out-patient and operative numbers. With regards to earnings, those working in private and running their own (individual) hospitals \& clinics have been most severely affected while those in government sector and medical colleges have been affected the least.

Keywords Novel coronavirus $\cdot$ COVID-19 $\cdot$ Pandemic $\cdot$ Orthopaedic $\cdot$ Practice $\cdot$ Online survey

\section{Introduction}

Coronavirus disease 2019 (COVID-19) spreads globally resulting in a pandemic after being first reported in Chinese city of Wuhan in December 2019 [1]. WHO officially declared it a pandemic on 12 March 2020. By 24 May 2020, there has been 5.46 million cases and over 345 thousand mortalities due to the disease [2]. Talking about India, till the same period, we had 131,868 cases out of which 3867 people have died [3]. Several measures were taken

\author{
Anurag Baghel \\ anuragbaghelatc@gmail.com \\ Kumar Keshav \\ keshav4700@yahoo.co.in \\ Amit Kumar \\ amit2k03@yahoo.co.in \\ Pulak Sharma \\ drpulaksharma@gmail.com \\ Prabhaker Mishra \\ mishrapk79@gmail.com \\ Najmul Huda \\ hudanajamul@gmail.com
}

1 Department of Orthopaedics, Apex Trauma Centre, Sanjay Gandhi Post Graduate Institite of Medical Sciences, Vrindavan Yojna, Rae Bareli Road, Lucknow PIN-226029, Uttar Pradesh, India

2 Department of Biostatistics and Health Informatics, Sanjay Gandhi Post Graduate Institite of Medical Sciences,

Vrindavan Yojna, Rae Bareli Road, Lucknow PIN-226029, Uttar Pradesh, India

3 Department of Orthopaedics, Teerthanker Mahaveer Medical College, Delhi Road, Moradabad PIN- 244001, Uttar Pradesh, India 
by government which included nationwide lockdown, promoting social distancing, establishment of new dedicated COVID-19 hospitals, contact tracing and quarantine facilities [3, 4]. Due to this, we have been able to slow down the spread of disease to a large extent. We have already entered into the seventh week of lockdown [5]. One can very well assume that even if lockdown is lifted off in the near future, it will take quite some time to go back to the pre-COVID-19 times. Nearly, all strata of people have been affected. Of special note is the healthcare facilities to non-COVID-19 patients which have been drastically affected. In one of the domains of healthcare, orthopaedic surgery has also been affected like other specialities. Guidelines for safe orthopaedic practice have been promoted by major international and national orthopaedic bodies [6-9]. Despite all these, we have witnessed a drastic fall in the number of patients we were seeing in Out-patient department (OPD) and operating upon. Ground-level data telling us the exact degree or extent to which orthopaedic practice in India has been affected are still missing. So, we felt the need to conduct a study to bring out these facts and figures. The aim of the study was to assess the extent to which the clinical practices of orthopaedic surgeons have been affected by the COVID19 pandemic in India, in terms of change in the number of outpatients seen and operative interventions performed as well as from financial point of view.

\section{Materials and Methods}

To achieve the above-mentioned aim, we decided to conduct an online survey targeting the practicing orthopaedic surgeons of India (those who had obtained their post-graduate degree/ diploma and were practicing in India before the COVID-19 pandemic broke out). Those orthopaedicians who were not practicing in India, or were still under training (residents/fellows) or had left clinical practice before the onset of pandemic were excluded from the study. We took utmost care to exclude the trainees because including them in the study would have meant possibility of duplication and bias of some kind. The study was designed after around 3 weeks of nationwide lockdown. It was given ethical clearance by Bioethics cell of our institute (Sanjay Gandhi Post Graduate Institute of medical Sciences, Lucknow), IEC Code-2020-133-IMP-EXP-20, following which survey questionnaires (either as Google forms ${ }^{\circledR}$ or Survey Monkey ${ }^{\circledR}$ questionnaire) were circulated. We informed our national orthopaedic body, Indian Orthopaedic Association (IOA), and got permission and details of its members to conduct the nationwide survey. The questionnaires were circulated as a link through mail and other social media platforms like WhatsApp ${ }^{\circledR}$ to the IOA members. All the potential participants were properly explained about the study in detail, and informed consent was taken. Only those who agreed to participate in the study could fill the survey form. To avoid duplication of submission, email ID was kept as a mandatory part of the questionnaire. Among those email IDs from which we received more than one submissions, only the last ones were included. The data, hence, gathered were compiled in Microsoft Excel ${ }^{\circledR}$ and Google sheets ${ }^{\circledR}$.

Questionnaire contents were validated by eight faculty members who rated the questionnaire for simplicity, clarity, ambiguity, and its relevance on a scale of 1 to 5 , where 1 was worst and 5 was best. There was good score observed (observed score with respect to maximum possible score expressed in \%) for each of the measurements, i.e. Simplicity $(36 / 40,90 \%)$, Clarity $(35 / 40,88 \%)$, Free of ambiguity $(30 / 40,75 \%)$, and relevance $(39 / 40,98 \%)$. The internal consistency of the questionnaire was assessed using Cronbach's alpha which was also showing good correlation between the questions (0.83) with maximum questions showing correlation with each other.

\section{Statistical Analysis}

Categorical variables were presented in frequency (\%). To test the association (comparison in proportion) between categorical variables like the sector, kind of set-up and the years of orthopaedic practice with various other variables of orthopaedic practices and financial aspects, Chi-square test was used (when each cell had at least 5 expected frequency), otherwise Fisher's exact test was used. $P$ values $<0.05$ have been considered as statistically significant. Graphs were prepared in Microsoft Excel 365 and Google sheets. Statistical package for social sciences version 23 (SPSS-23, IBM, Chicago, USA) was used for data analysis.

\section{Observation and Results}

A total of 533 practicing orthopaedic surgeons took part in the study. Out of these, complete responses were obtained from 407 individuals and these were used to analyse the results (Fig. 1). The study participants belonged to 27 states and union territories of India (out of 36) including Uttar Pradesh $(n=148,36.4 \%)$, followed by Maharashtra $(n=39$, 9.6\%), Tamil Nadu $(n=36,8.8 \%)$ and Gujrat $(n=27,6.6 \%)$. Mean and Median age of the study participants were 43.7 and 41 years, respectively (range 27-65 years) (Fig. 2). Most of the orthopaedicians belonged to age group of 30-50 years $(n=270,66.3 \%)$, followed by $\geq 50$ years $(n=129,31.7 \%)$ and $<30$ years $(n=8,2 \%)$. Years of practice were ranging between 10 and 20 years $(n=111,27.3 \%)$, followed by $5-10$ years $(n=103,25.3 \%)$, whereas almost equal proportions of the orthopaedic clinical practice were ranging among $<5$ years $(n=65,16 \%), 20-30$ years and $>30$ years 


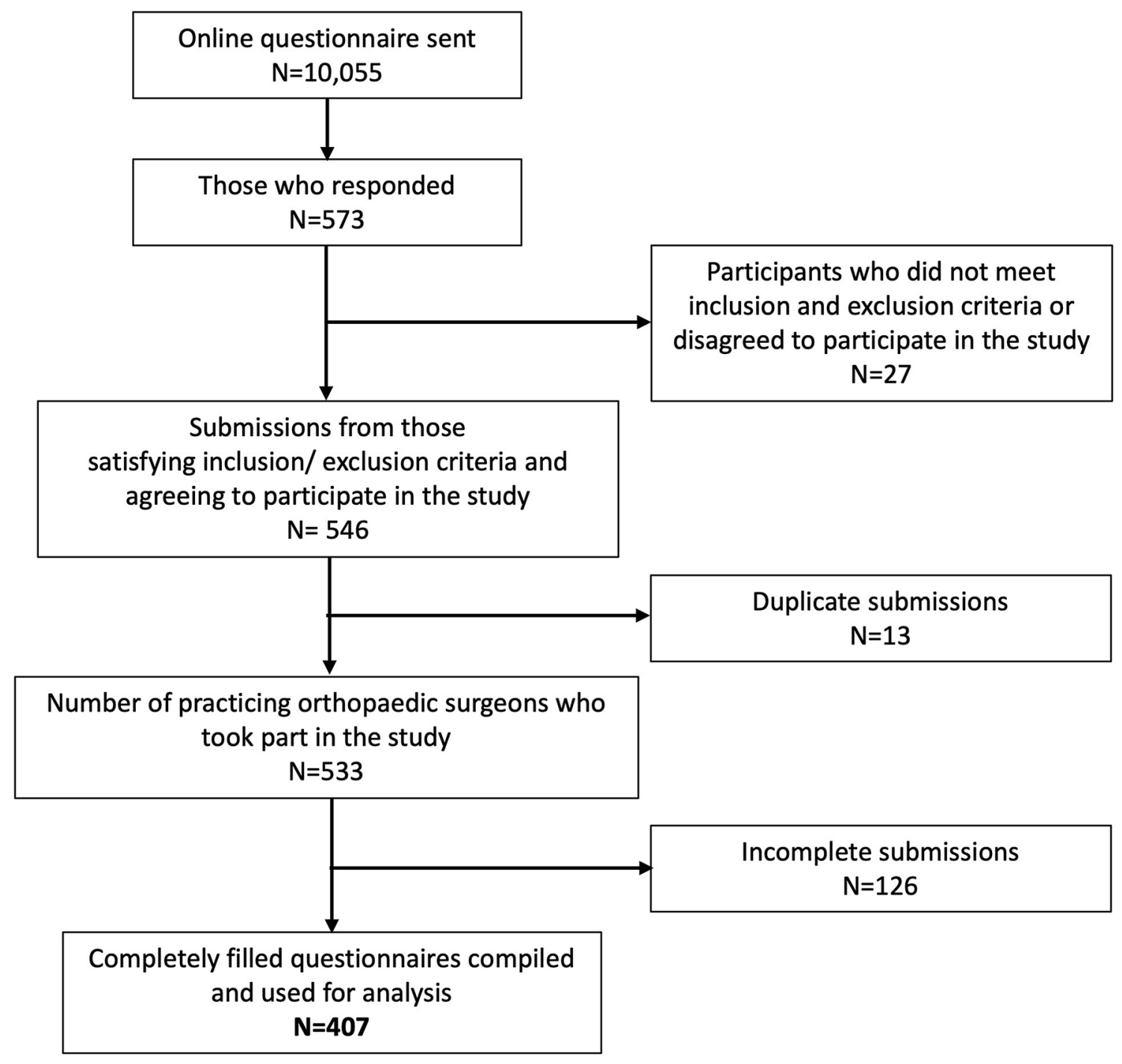

Fig. 1 Flowchart of the study design

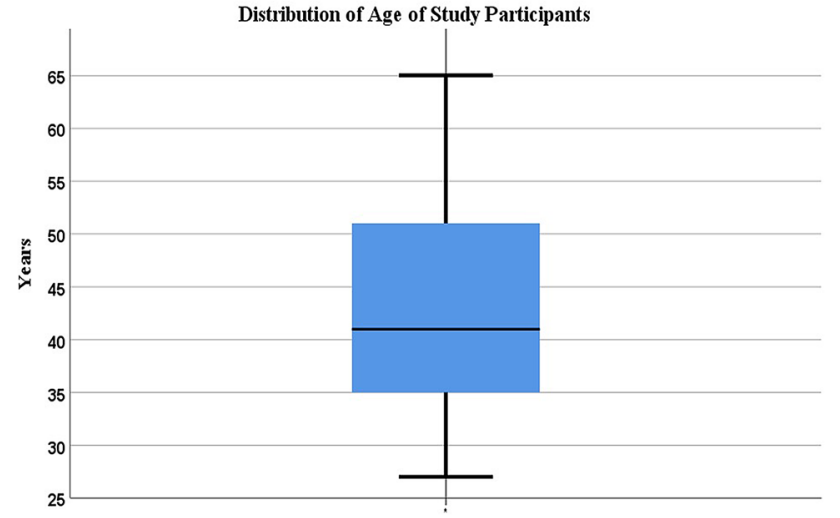

Fig. 2 Box plot showing distribution of age of the study participants (each $n=64,15.7 \%$ ) (Fig. 3a). A little less than 3/4th of doctors $(n=293,72 \%)$ were working in private sector followed by $1 / 5$ th $(n=76,18.7 \%)$ in government sector, and the rest in both $(n=37,9.3 \%)$ (Fig. 3b). Majority were working in multi/super speciality hospitals $(n=131,32.3 \%)$ followed by individual (own) hospital $(n=116,28.6 \%)$ and medical colleges $(n=115,28.3 \%)$, whereas $8.6 \%(n=35)$ were freelancers, $1.2 \%(n=5)$ were working in district hospital or small government hospitals, and $1.6 \%$ were practicing in their own clinics ( $n=4,1 \%$ ) (Fig. 3c). Majority were primarily dealing with trauma $(n=268,65.8 \%)$, followed by arthroplasty $(n=51,12.5 \%)$, arthroscopy and sports medicine $(n=29$, $7.1 \%)$ and spine $(n=26,6.4 \%)$. (Table 1$)$.

As far as OPD is concerned, before the onset of pandemic, $39.8 \%(n=162)$ of the respondents had their monthly numbers between 100 and 500, 20.4\% $(n=83)$ had between 500 and 1000 , and $11.5 \%(n=47)$ had more than 1000 . 


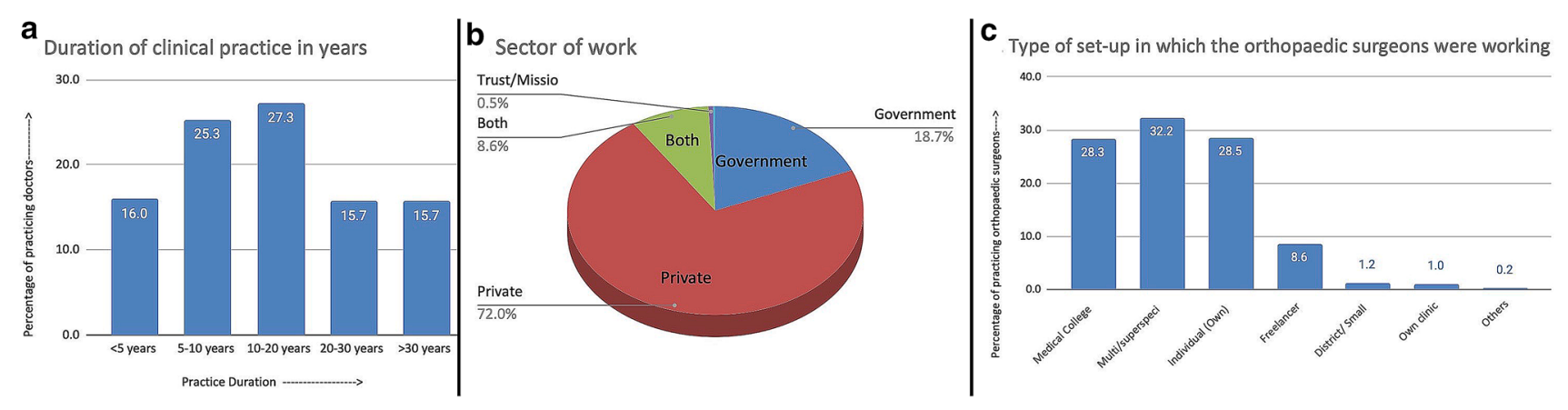

Fig. 3 The demographic profile of the study participants

Table 1 Demography of clinical practices of orthopaedic surgeons $(N=407)$

\begin{tabular}{ll}
\hline Variable & Summary statistics $(N=407)$ \\
\hline Participants from States & $\begin{array}{c}27(\text { Out of } 36 \text { states including } \\
\text { UTs })\end{array}$ \\
Age groups (years) & \\
$<30$ & $8(2 \%)$ \\
$30-50$ & $270(66.3 \%)$ \\
$>50$ & $129(31.7 \%)$ \\
Years of practice & \\
$<5$ & $65(16 \%)$ \\
5-10 years & $103(25.3 \%)$ \\
10-20 years & $111(27.3 \%)$ \\
20-30 & $64(15.7 \%)$ \\
$>30$ & $64(15.7 \%)$ \\
Sector of work & \\
Private & $293(72 \%)$ \\
Government & $76(18.7 \%)$ \\
Both government and private & $35(8.6 \%)$ \\
Type of set-up & \\
Multi/ super speciality hospitals & $131(32.2 \%)$ \\
Individual (own) hospital & $116(28.5 \%)$ \\
Medical colleges & $115(28.3 \%)$ \\
Freelancers & $35(8.6 \%)$ \\
Small government hospitals & $5(1.2 \%)$ \\
Own clinic & $4(1.0 \%)$ \\
Specialization & $268(65.8 \%)$ \\
Trauma & $51(12.5 \%)$ \\
Arthroplasty & $29(7.1 \%)$ \\
Arthroscopy and sports medicine & $26(6.4 \%)$ \\
Spine & \\
\hline
\end{tabular}

Data are given in frequency (\%)

Due to the pandemic, these data were drastically affected; $7.6 \%(n=31)$ had stopped any form of consultations, $18.4 \%$ $(n=75)$ were giving only telemedicine consultations, $28 \%$ $(n=114), 25.6 \%(n=104)$ and $15.2 \%(n=62)$ experienced fall in out-patients cases more than $90 \%, 75 \%$ and $50 \%$, respectively (Fig. 4a). If we look at the number of emergency cases, mainly involving trauma and tumour, majority $(n=157,38.6 \%)$ were operating $10-30$ cases per month before the onset of pandemic. During the pandemic, $1 / 5$ th ( $n=85,20.9 \%$ ) of the orthopaedists had stopped doing them altogether, $2 / 5$ th $(n=170,41.7 \%)$ had more than $90 \%$ reduction and another $1 / 5$ th $(n=88,21.6 \%)$ by around $75 \%$. If we see these numbers in elective surgeries, pre-COVID, the numbers almost mimicked the emergency counterparts, with most of the doctors operating 10-30 cases per month $(n=157)$, followed by those doing $5-10$ per month $(n=127)$. But in contrast to the emergency cases, a whopping 63.9\% $(n=260)$ of orthopaedic surgeons had stopped doing elective cases completely (Fig. 4b). Although the patients themselves could have assessed better, but what our surgeons felt was that those severely affected due to the pandemic were $41 \%$ $(n=167)$ and 53\% $(n=216)$ amongst emergency and nonemergency groups, respectively. The figures with regard to those moderately affected were $39 \%(n=159)$ and $30.5 \%$ $(n=124)$, respectively, (Fig. 4c; Table 2).

This fall in numbers had an obvious reciprocating effect on the financial aspects as well. $28 \%(n=114)$ of the doctors, mainly belonging to the private sector and running their individual (own) hospitals saw their income going down by $>90 \%$. Those who saw their fortunes falling by $75 \%$ and $50 \%$ constituted around $1 / 5$ th $(n=83,20.4 \%)$ and $1 / 4$ th $(n=96,23.4 \%)$, respectively. Those $1 / 5$ th $(n=75,18.4 \%)$ whose earnings almost remained the same were mainly those working in government sector $(n=59 / 75,78.6 \%)$. Interestingly, there were still $0.5 \%(n=2)$ of the individuals whose incomes went up (Fig. 4d; Table 2). Despite this unsettling picture, humanity kept its head held high as almost $65 \%$ ( $n=166 / 256)$ of the practicing orthopaedicians who had employees working under them were paying salaries same as before the onset of pandemic. Only a quarter $(n=64 / 256)$ were either giving reduced pay or had curtailed the number of employees. Another 7.4\% ( $n=19 / 256)$ were giving salary in full but over a prolonged period of time. Just a meagre 


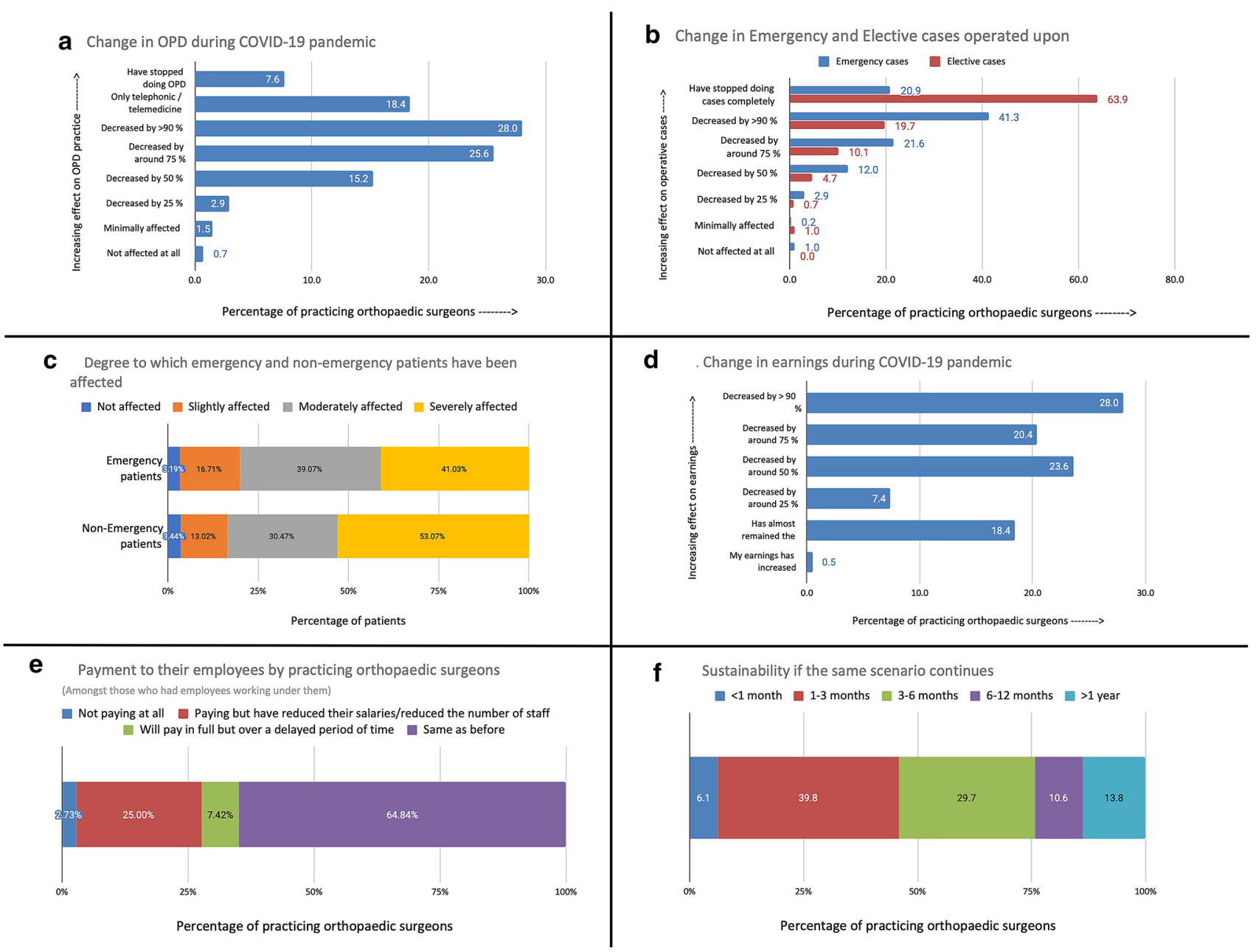

Fig. 4 a-f Changes in various parameters of orthopaedic practice brought about by COVID-19 pandemic

2.7\% $(n=7 / 256)$ had stopped paying salaries altogether (Fig. 4e).

But with the orthopaedic practice coming to an almost standstill as mentioned above, things cannot be expected to continue like this for too long. When we asked the participants as for how long could they continue like that, majority $(40 \%)(n=162)$ answered for $1-3$ months while another $30 \%(n=121)$ went in for 3-6 months. Only $14 \%(n=56)$ respondents opined that they could continue beyond an year (Fig. 4f).

We tried to find out if there was any significant association between (1) sector (government, private, etc.), (2) the kind of set-up (medical college, multispeciality hospital, individual (own) hospital, etc.) one was working at, (3) the years of orthopaedic practice and various parameters of orthopaedic practice: number of OPD patients, emergency and elective cases performed, effect on patients, earnings and sustainability. We found a significant association between the change (decrease) in earnings with both the sector $(p$ value $<0.001)$ and type of hospital/set-up an orthopaedic surgeon was working at ( $p$ value $<0.001)$. As far as sector is concerned, those in private sector and those working in both government and private were worst hit. With type of working set-up, there was drastic fall amongst those with individual hospitals and clinics and those working in multi/superspeciality hospitals. With regard to the sustainability, a significant association was found with the type of sector $(p$ value $<0.05)$ but not with the type of set-up ( $p$ value $>0.05$ ). Apart from this, a significant association was also found between the earnings affected and years of practice. Those with more years of practice between $20-30$ years and beyond 30 years have been affected more as compared to their younger counterparts ( $p$ value $<0.001)$ (Fig. 5).

\section{Discussion}

As of now, not much clinical and pathological (skeletal muscle and joint biopsy) data about COVID-19 related to orthopaedics are available because this is a disease which 
Table 2 Summary of the impact of COVID-19 pandemic on orthopaedic practice in India $(N=407)$

\begin{tabular}{|c|c|}
\hline Variables & Frequency $(\%)$ \\
\hline \multicolumn{2}{|l|}{ OPD cases pre-pandemic } \\
\hline$<100$ & $115(28.3 \%)$ \\
\hline $100-500$ & $162(39.8 \%)$ \\
\hline $500-1000$ & $83(20.4 \%)$ \\
\hline$>1000$ & $47(11.5 \%)$ \\
\hline \multicolumn{2}{|l|}{ OPD cases during pandemic } \\
\hline Stopped any form of consultations & $31(7.6 \%)$ \\
\hline Giving only telemedicine consultations & $75(18.4 \%)$ \\
\hline Fall in out-patients more than $90 \%$ & $114(28 \%)$ \\
\hline Fall in out-patients by around $75 \%$ & $104(25.6 \%)$ \\
\hline Fall in out-patients by around $50 \%$ & $62(15.2 \%)$ \\
\hline \multicolumn{2}{|l|}{ Change in operative cases (Emergency ones) } \\
\hline Stopped doing them altogether & $85(20.9 \%)$ \\
\hline More than $90 \%$ reduction & $168(41.3 \%)$ \\
\hline Around $75 \%$ reduction & $88(21.6 \%)$ \\
\hline Around $50 \%$ reduction & $49(12 \%)$ \\
\hline \multicolumn{2}{|l|}{ Change in operative cases (Elective ones) } \\
\hline Stopped doing them altogether & $260(63.9 \%)$ \\
\hline More than $90 \%$ reduction & $80(19.7 \%)$ \\
\hline Around $75 \%$ reduction & $41(10.1 \%)$ \\
\hline Around $50 \%$ reduction & $19(4.7 \%)$ \\
\hline \multicolumn{2}{|c|}{ Extent to which emergency patients were affected } \\
\hline Severely affected & $167(41 \%)$ \\
\hline Moderately affected & $159(39 \%)$ \\
\hline \multicolumn{2}{|c|}{ Extent to which non-emergency patients were affected } \\
\hline Severely affected & $216(53 \%)$ \\
\hline Moderately affected & $124(30.5 \%)$ \\
\hline \multicolumn{2}{|l|}{ Decrease in earnings } \\
\hline By $>90 \%$ & $114(28 \%)$ \\
\hline Around $75 \%$ & $83(20.4 \%)$ \\
\hline Around $50 \%$ & $96(23.6 \%)$ \\
\hline Around $25 \%$ & $30(7.4 \%)$ \\
\hline Almost remained the same & $\begin{array}{l}75(18.4 \%) \text { [Of } \\
\text { these, } 78.6 \% \text { from } \\
\text { Govt. sector] }\end{array}$ \\
\hline Income went up & $2(0.5 \%)$ \\
\hline
\end{tabular}

Data are given in frequency $(\%)$ primarily does not affect the musculoskeletal system. Cipollaro et al.in a review article emphasized that myalgia, arthralgia and fatigue are the musculoskeletal manifestations but asserted it to be a part of generalized inflammatory response of the body [10]. However, due to the pandemic nature of this disease and transmission being air-borne, it has affected our speciality beyond what can be gauged from the nature of the disease per se. The measures taken by the Indian government have been instrumental to some extent in flattening the curve of the pandemic [3-5]. Most of the human, infrastructural and financial resources have been directed to somehow control this pandemic. One of the downside of these measures have been the tremendous amount of trouble it has caused to the non-COVID patients. Routine OPDs were shut down in most of the states leaving them aghast with agony [11].

If we look at the publications related to COVID-19 and orthopaedic surgery, most of them have been either guidelines or author's opinions or letter to the editor or commentaries [12-17]. But the sudden onset of epidemic has given us very little time, if any to embrace the change required to be done. Along with this, the nationwide lockdown and the government directives to stop routine OPDs, although for a short time, have left all the patients waiting. Together with the medical pandemic, there has been a corresponding infodemic as well [16]. We are constantly hearing newer 


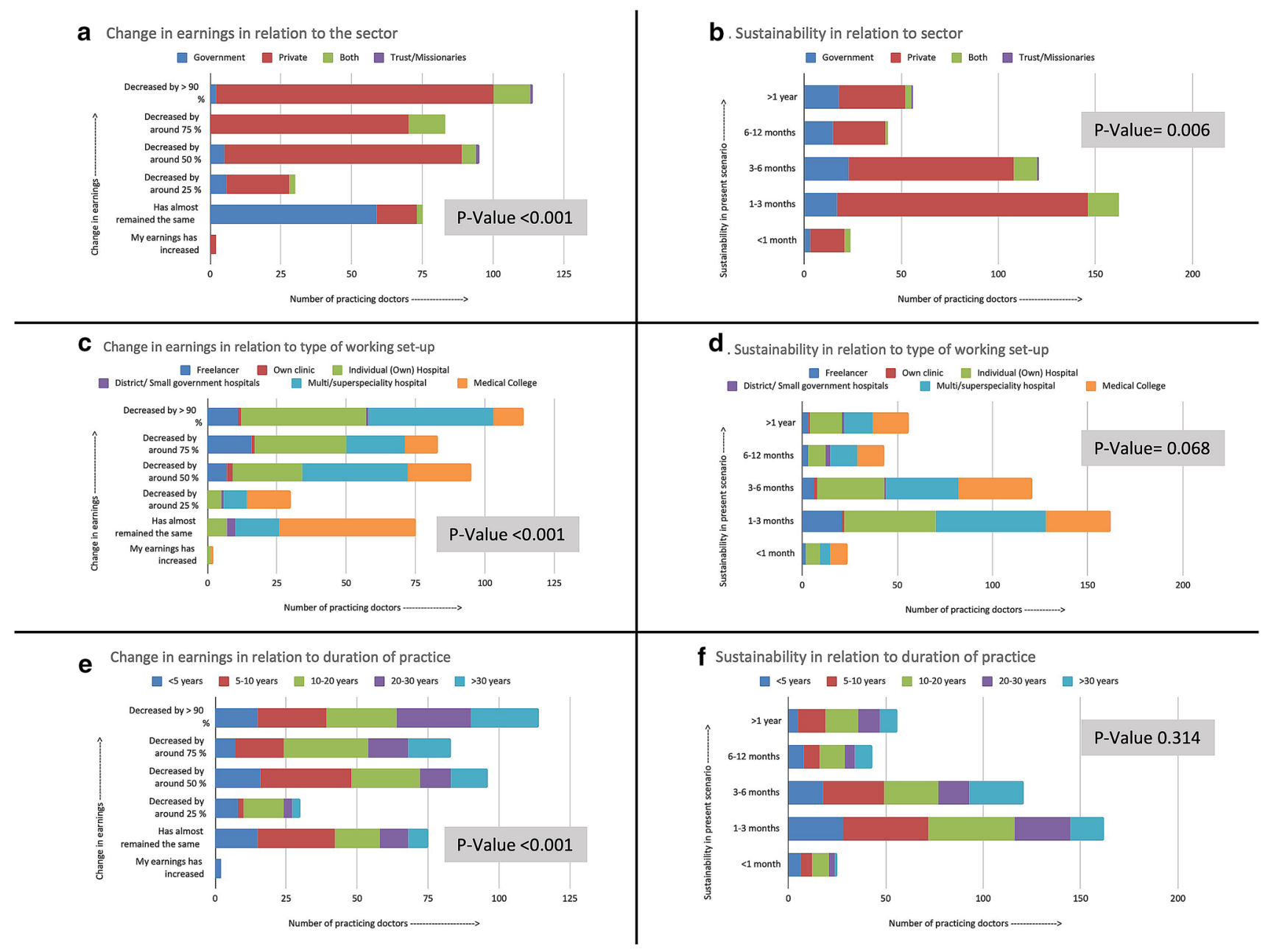

Fig. 5 a-f Graphical representation of changes in earnings and sustainability in relation to sector, kind of working set-up and duration of orthopaedic practice

and newer guidelines and that have caused a lot of confusion $[6-9,12,13,20]$. Many of the guidelines that have been advised will indeed require time to be complied with. Till the time we start enacting upon these guidelines both in verbatim and in spirit, orthopaedic practice is expected to go downhill.

The fall in OPD numbers, as opined by the respondents in our study, has mainly been due to 3 reasons: (1) doctors do not want to take risk without proper screening measures in place, (2) patients are not turning up in the fear of contracting the disease and (3) and those patients who indeed want to get a consultation are unable to reach hospital due to cancellation of public transport facilities. Patients, especially the older ones and those with comorbidities are willing to continue with pain relieving over-the-counter medications rather than venturing out. For those OPD cases which do not require an actual physical examination, telemedicine is a viable option in near future. Many of the guidelines have pointed to that $[13,20]$. What we can do is to first address all potential OPD patients through telemedicine and only those patients who indeed require a physical examination, to be called for actual physical OPD. Mann et al.in a study found that the telemedicine facilities saw an unprecedented rise during the pandemic [21].

Emergency cases, the major portion of which is orthopaedic trauma, have indeed gone down appreciably due to less number of road traffic accidents [22]. But this picture is soon going to change as the lockdown has been eased, which will give an opportunity for more and more people to use their vehicles for transport. Elective cases can be deferred to create hospital areas/beds for COVID-19 patients, as mentioned in many of the guidelines [13, 19]. However, this cannot be done indefinitely. One of the practical things that has been implemented already in most of the hospitals in our country and around the globe is getting a COVID-19 RT-PCR done and only when the report comes negative, the patient to be taken for surgery [20]. The silver lining for our speciality is that most of the trauma patients having isolated injuries to 
the extremities can be managed conservatively till the report is negative. This approach can be labelled as "Converting an emergency to some sort of semi-emergency". Orthopaedic surgical procedures usually require giving incisions, handling soft tissues and bones, drilling and reaming, application of hardwares, washing \& debridement and closure of wounds. Most of these are aerosol-generating procedures. Some of the recent literatures have pointed out the possibility of novel Coronavirus transmission through these aerosols [23]. And, hence, we need to be extra cautious while venturing in OT for performing surgeries. Considering the fact that RT-PCR has a false-negative rate of almost 20\%, [24, 25] all the surgeries should be done wearing PPE kits [26]. In our survey, we found that $65 \%$ of the practicing doctors in India were having adequate supply of N95 masks and PPE kits. However, still $20 \%$ were not getting it in adequate supply, something which needs to be pondered about.

As the resources have been channelized towards care of COVID-19 due to obvious reasons, we have to find some ways to maximize the optimum use of available resources. Drawing an exact boundary between the real emergency cases, where we cannot delay giving the operative treatment at all, the semi-elective and elective ones are the need of the hour. In most of the hospitals, a part was created for specific handling of COVID-19 patients. This has led to decrease in the number of beds dedicated for orthopaedic speciality. So, turnover of the patients has to be increased. Liang et al., while sharing their experiences from Singapore have mentioned that they continued addressing urgent cases (trauma and tumour) at the earliest possible setting and continued doing the elective surgeries which required $<24 \mathrm{~h}$ of admission like the arthroscopic surgeries [12].

Coming over to the finances, there is a plethora of causes leading to decreased inflow of patients starting from rising unemployment especially among the daily wage earners to actual inability to reach the hospitals due to unavailability of means of public transport. With the economic growth of the country going in negative, we cannot expect ourselves to remain untouched by it. Anoushuavani et al. addressed the orthopaedic perspective of economic aspects of COVID-19. They said that the health care system of US relied heavily on elective surgical procedures like hip and knee arthroplasties, laminectomies and spinal fusion procedures. All these along with treatment of lower limb fracture and dislocations accounted for $17 \%$ of all operative room procedures [27]. In India also, a major chunk of health revenues which are generated by the medical tourism depend solely on these procedures. As international flights have been cancelled, this medical tourism, which is an industry in its own right has come to a standstill. Corporate hospitals, which are the main centres of medical tourism have suffered huge losses and had to withhold a part of the surgeons' pays and furlough many of its employees. To tide over the crisis, few steps need to be taken. To start with, telemedicine should be monetised. Elective surgeries can be restarted in a phased manner with the precautions as mentioned above and highlighted in many of the papers. We need the hospitals to keep running because closure of hospitals would essentially mean unemployment for not only the consulting doctors, but also the entire healthcare staff, eventually taking the healthcare economy in a downward spiral. Our data show the plight of individual hospital owners working in private sector most of whom are already riddled with loans and staffs to be paid for, who will have real difficulty in keeping their shutters open. They can restart their services after bringing about proper changes in the design of their hospitals based on the guidelines and implementing safe-practice guidelines [6-9, 12, 20]. We also had a statistically significant association of increasing years of orthopaedic practice and decrease in earnings. It may be due to the reason that older people are less likely to venture out and take risks because of their higher vulnerability to COVID-19.

This study, we believe is the first of its kind done in India specifically to address the quantum of change that orthopaedic practice has undergone after the onset of COVID-19 pandemic. The salient findings to come out from our study are: (1) More than half of the practicing surgeons witnessing fall in OPD over 90\%, (2) Most of the surgeons stopping elective surgeries and even emergency ones altogether, leading to patients getting profoundly affected, (3) More than 50\% of doctors having their earnings reduced by $>75 \%$, but majority still continuing to pay their employees, (4) A statistically significant association of reduction in incomes with the sector, type of set-up in which they were working and duration of practice, and (5) The unsustainable picture of orthopaedic practice if we continue in a similar manner and do not take efforts to revive our practice. In these pressing times, we are walking through a tunnel but let us hope that like always, there is light at the end of the tunnel. All changes are hard at first, messy in the middle and gorgeous in the end.

\section{Conclusion}

The present study suggests that the COVID-19 pandemic has caused a significant impact on the orthopaedic practice in India. Orthopaedic surgeons working in all the sectors across different types of set-ups have been affected in terms of their out-patient and operative numbers. With regard to earnings, practicing orthopaedic surgeons working in private sector and running their own (individual) hospitals and clinics have been most severely affected, while those working in government sector and medical colleges have been affected the least. The future of orthopaedic practice in COVID-19 times is no doubt challenging both from health and materialistic 
point of view, but with the right approach and guidelines as laid down by major orthopaedic bodies, are indeed revivable.

\section{Funding None.}

\section{Compliance with Ethical Standards}

Conflict of interest The authors declare that they have no conflict of interest.

Ethical standard statement This article does not contain any studies with human or animal subjects performed by the any of the authors.

Informed consent For this type of study informed consent is not required.

\section{References}

1. Wang, C., Horby, P. W., Hayden, F. G., \& Gao, G. F. (2020). A novel coronavirus outbreak of global health concern. Lancet, 395(10223), 470-473.

2. World health Organization. Coronavirus (Covid-19). Available at: https://www.who.int/emergencies/diseases/novel-coronaviru s-2019 Accessed 24 May 2020.

3. Ministry of Health and Family Welfare, Government of India. COVID-19 India. Available at: www.mohfw.gov.in Accessed 24 May 2020.

4. Lancet, T. (2020). India under COVID-19 lockdown. Lancet, 395(10233), 1315.

5. Centre extends nationwide lockdown till May 31, new guidelines issued. Tribuneindia News Service (Internet). 2020. Available from: https://www.tribuneindia.com/news/nation/centr e-extends-nationwide-lockdown-till-may-31-new-guidelines -issued-86042 Accessed 17 May 2020.

6. British Orthopaedic Association. Management of patients with urgent Orthopaedic conditions and trauma during the coronavirus pandemic. London: British Orthopaedic Association, 2020. Available at: https://www.boa.ac.uk/resources/covid-19-boast s-combined.html. Accessed 25 May 2020.

7. Alliance of International Organizations of Orthopaedics and traumatology. COVID-19 Best Practices Joint Statement. Available at: https://www.apoaonline.com/pdf/aiot-joint-statement. pdf Accessed April 27, 2020.

8. The Surgical Royal Colleges of the United Kingdom and Ireland. Guidance for surgeons working during the COVID-19 pandemic. London: The Surgical Royal Colleges of the United Kingdom and Ireland, 2020. Available at: https://www.rcsen g.ac.uk/coronavirus/joint-guidance-for-surgeons/. Accessed 25 May 2020.

9. Indian Orthopaedic Association. COVID-19 IOA guidelines. New Delhi: Indian Orthopaedic Association, 2020. Available at: https://www.ioaindia.org/COVID-19IOAguidelines.pdf. Accessed 25 May 2020.

10. Cipollaro, L., Giordano, L., Padulo, J., Oliva, F., \& Maffulli, N. (2020). Musculoskeletal symptoms in SARS-CoV-2 (COVID19) patients. J Orthop Surg Res, 15(1), 178.

11. Hospital visits a big ask for non-corona patients amid lockdown. The times of India (Internet). 2020 Available at: https://times ofindia.indiatimes.com/india/hospital-visit s-a-big-ask-for-non-corona-patients-amid-lockdown/articlesho w/75493258.cms Accessed on 25 May 2020.

12. Chang Liang, Z., Wang, W., Murphy, D., \& Po Hui, J. H. (2020). Novel coronavirus and orthopaedic surgery: early experiences from Singapore. Journal of Bone and Joint Surgery. American Volume, 102(9), 745-749.

13. Chou, A. C. C., Akagi, R., Chiu, J. C.-H., Han, S., \& Lie, D. T. T. (2020). The impact of coronavirus disease 2019 (COVID-19) on orthopaedic practice: perspectives from Asia-Pacific. The Transient Journal of Trauma, Orthopaedics and the Coronavirus. Available at: https://www.boa.ac.uk/policy-engagement /journal-of-trauma-orthopaedics/journal-of-trauma-ortho paedics-and-coronavirus/the-impact-of-coronavirus-disease2019-covid-19.html. Accessed 25 May 2020.

14. Haleem, A., Javaid, M., Vaishya, R., \& Vaish, A. (2020). Effects of COVID-19 pandemic in the field of orthopaedics. J Clin Orthop Trauma, 11(3), 498-499.

15. Jain, V. K., \& Vaishya, R. (2020). COVID-19 and orthopaedic surgeons: the Indian scenario. Trop Dr, 50(2), 108-110.

16. Bagaria, V., \& Sahu, D. (2020). Orthopaedics in times of COVID 19. Indian J Orthop., 54(3), 400-401.

17. Neradi, D., Hooda, A., Shetty, A., Kumar, D., Salaria, A. K., \& Goni, V. (2020). Management of orthopaedic patients during COVID-19 Pandemic in India: a guide. Indian J Orthop., 54(3), 402-407.

18. Cuan-Baltazar, J. Y., Muñoz-Perez, M. J., Robledo-Vega, C., Pérez-Zepeda, M. F., \& Soto-Vega, E. (2020). Misinformation of COVID-19 on the internet: infodemiology study. JMIR Public Health Surveill, 6(2), e18444.

19. Placella, G., Salvato, D., Delmastro, E., Bettinelli, G., \& Salini, V. (2020). CoViD-19 and ortho and trauma surgery: the Italian experience. Injury, 51(6), 1403-1405. (published online ahead of print, 2020 Apr 15).

20. Stinner, D. J., Lebrun, C., Hsu, J. R., Jahangir, A. A., \& Mir, H. R. (2020). The orthopaedic trauma service and COVID-19practice considerations to optimize outcomes and limit exposure. Journal of Orthopaedic Trauma. https://doi.org/10.1097/ BOT.0000000000001782. (published online ahead of print, 2020 Apr 13).

21. Mann, D. M., Chen, J., Chunara, R., Testa, P. A., \& Nov, O. (2020). COVID-19 transforms health care through telemedicine: evidence from the field. Journal of the American Medical Informatics Association: JAMIA, 27(7), 1132-1135. https://doi. org/10.1093/jamia/ocaa072.

22. Coronavirus lockdown: Mumbai reports drop in death toll due to rail, road accident during pandemic. India Today (Internet). 2020 Available from: https://www.indiatoday.in/india/story/ coronavirus-lockdown-impact-mumbai-deaths-rail-road-accid ent-covid-pandemic-1671569-2020-04-27 Accessed 25 May 2020.

23. van Doremalen, N., Bushmaker, T., Morris, D. H., et al. (2020). Aerosol and surface stability of SARS-CoV-2 as compared with SARS-CoV-1. N Eng J Med, 382(16), 1564-1567.

24. Xiao, A. T., Tong, Y. X., \& Zhang, S. (2020). False-negative of RT-PCR and prolonged nucleic acid conversion in COVID-19: Rather than recurrence. Journal of Medical Virology. https:// doi.org/10.1002/jmv.25855. (published online ahead of print, 2020 Apr 9).

25. Kucirka, L. M., Lauer, S. A., Laeyendecker, O., Boon, D., \& Lessler, J. (2020). Variation in false-negative rate of reverse transcriptase polymerase chain reaction-based SARS-CoV-2 tests by time since exposure. Annals of Internal Medicine. https ://doi.org/10.7326/M20-1495.

26. Hirschmann, M. T., Hart, A., Henckel, J., Sadoghi, P., Seil, R., \& Mouton, C. (2020). COVID-19 coronavirus: recommended personal protective equipment for the orthopaedic and trauma 
surgeon. Knee Surgery, Sports Traumatology, Arthroscopy, 28(6), 1690-1698.

27. Anoushiravani, A. A., O'Connor, C. M., DiCaprio, M. R., \& Iorio, R. (2020). Economic impacts of the COVID-19 crisis: an orthopaedic perspective. The Journal of Bone and Joint Surgery. American Volume, 102(11), 937-941. https://doi. org/10.2106/JBJS.20.00557.
Publisher's Note Springer Nature remains neutral with regard to jurisdictional claims in published maps and institutional affiliations. 